Єфімчук Г. В., Назарчук Л. В., Селезньов Е. Л., Клименко О. Д., Селезньов Д. Е., Шимчук Ю. П. Луиький національний технічний університет, м. Луцьк, Украйна

\title{
ОПТИМІЗАЦІЯ ПРОЦЕСУ ВІДМОЧУВАННЯ ПРІСНОСУХОЇ СИРОВИНИ ПІД ВПЛИВОМ ЕЛЕКТРОАКТИВОВАНИХ ВОДНИХ СЕРЕДОВИЩ
}

\footnotetext{
У статті представлено планування двохфакторного експерименту, в результаті якого встановлено оптимальні режими процесу відмочування хутрової сировини. Запропоновано практичні рекомендації використання електроактивованих водних розчинів під час проведення технологічних процесів обробки хутрової сировини, а також визначено раціональні технологічні параметри проведення підготовчих процесів вичинки хутра.

Ключові слова: відмочування, хутрова сировина, $\mathrm{pH}$ водного розчину, електроактивована вода.
}

Планування другого порядку використовують на практиці в тих випадках, коли лінійного приближення недостатньо для математичного опису об'єкту досліджень з необхідною точністю. Тому виникає необхідність в побудові моделей у вигляді поліномів другої степені [1].

Постановка проблеми. Основна задача, яку необхідно вирішити під час проведення експерименту, - це підібрати такі значення водневого показника і температури відмочувальної рідини, при яких значення вологовмісту зразка було б максимальним. Іншими словами, потрібно знайти оптимальні режими проведення процесу відмочування, при яких би основна його задача (приведення консервованої шкурки в стан, близький до парного) виконувалась 3 найменшими затратами часу та електроенергії [1].

Об'єкти та методи дослідження. Об'єктом дослідження було обрано шкіру кроля прісносухого способу консервування. Дослідження по відмочуванню хутрової сировини [2] проводились в режимах, що відповідали матриці рототабельного планування експерименту другого порядку. Експериментальні дані оброблялись 3 допомогою оболонки МаthCAD. Результати математичного моделювання представлені у вигляді таблиць та графіків.

Критерієм оптимізації процесу відмочування шкурок кроля прісносухого методу консервування $\epsilon$ вологовміст зразків $(\mathrm{W}, \%)$, на який суттєво впливають температура $\left(\mathrm{t},{ }^{\circ} \mathrm{C}\right)$ та водневий показник (рН) відмочувальної рідини.

Результати та їх обговорення. Попередні досліди показали [3], що найбільші значення функції відгуку досягаються при водневому показнику близько 3,0 (аноліт) та температурі робочої рідини $50{ }^{\circ} \mathrm{C}$. Тому ці значення факторів були обрані за такі, що відповідають нульовому рівню при плануванні експерименту.

Значення факторів та їх кодування наведено у табл. 1.

Таблиця 1. Інтервали та рівні варіювання факторів критерію оптимізації в кодованих та натуральних величинах

\begin{tabular}{|l|c|c|c|c|c|c|}
\hline \multirow{2}{*}{ Фактори } & \multicolumn{5}{|c|}{ Рівні варіювання факторів } & \multicolumn{1}{c|}{$\begin{array}{c}\text { Інтервал } \\
\text { варіювання } \varepsilon\end{array}$} \\
\cline { 2 - 7 } & $-1,41$ & -1 & 0 & +1 & $+1,41$ & 1 \\
\hline Водневий показник $\mathrm{pH}\left(x_{1}\right)$ & 1,6 & 2 & 3 & 4 & 4,4 & 21,3 \\
\hline $\begin{array}{l}\text { Температура робочої } \\
\text { рідини } \\
\mathrm{t},{ }^{\circ} \mathrm{C}\left(x_{2}\right)\end{array}$ & 20 & 28,7 & 50 & 71,3 & 80 & \\
\hline
\end{tabular}

Загальна кількість дослідів N визначалась згідно [1], тому для двох факторів (k=2) N=13.

Статистична обробка даних по кожному досліду підтвердила, що вибірка не містить даних, які б відрізнялись від інших настільки, що б виникло припущення про грубу помилку. Таким чином, 3 вибірки не були викинуті дані експериментів.

Розрахунки середнього арифметичного значення критерію оптимізації в окремому досліді $\overline{y_{u}}$, дисперсії $s_{i}$ та величини похибок $\Delta y$ в кожному досліді, а також визначення довірчих інтервалів $\bar{y}_{u}+\Delta y$ i $\bar{y}_{u}-\Delta y$ здійснювалось згідно [1].Отримані результати було використано для перевірки 
однорідності дисперсій за критерієм Кохрена, який знаходиться із відношення максимальної дисперсії до суми всіх дисперсій:

$$
G_{\text {розр }}=\frac{s_{\max }^{2}}{\sum_{1}^{N} s_{i}^{2}}=0,1657
$$

Всі дисперсії можна вважати однорідними з довірчою імовірністю 95\%, так як $G_{\text {розр }}<G_{\text {табл }}$ при $G_{\text {табл }}=0,3095$ [2].

Для розрахунку коефіцієнтів рівняння регресії згідно $[4,5]$ проводились попередні розрахунки, в результаті чого були одержані розрахункові значення коефіцієнтів рівняння регресії. Після оцінки похибок при визначенні коефіцієнтів регресії та перевірки їх значимості було виявлено один не значимий коефіцієнт, а тому він може бути виключений із подальшого розгляду моделі. 3 урахуванням цього, рівняння регресії для кодованих факторів матиме вигляд:

$$
y\left(x_{1}, x_{2}\right)=146,7658-4,0386 x_{2}-2,5406 x_{1} x_{2}-3,074 x_{1}^{2}-8,5704 x_{2}^{2}
$$

Гіпотезу про адекватність моделі (2) перевіряли 3 допомогою критерію Фішера за методикою, описаною в [6]. 3 цією метою, знаходили значення дисперсій адекватності $s_{a d}^{2}$ та відтворюваності $s_{\{y\}}^{2}$ : $s_{a d}^{2}=142,9741 ; \quad s_{\{y\}}^{2}=98,9268$. Знаючи значення вищеприведених дисперсій, було знайдено розрахункове значення критерію Фішера:

$$
F_{\text {розр }}=\frac{s_{a d}^{2}}{s_{\{y\}}^{2}}=1,4453
$$

Порівнюючи розрахункове значення 3 табличним $F_{\text {табл }}=6,59 \quad\left(F_{\text {розр }}<F_{\text {табл }}\right), 3$ довірчою імовірністю 95\% можна стверджувати, що математична модель адекватно описує поверхню відгуку і iii можна використовувати з метою оптимізації процесу.

Відповідно до математичної моделі (2) за допомогою оболонки МathCAD були побудовані геометричні залежності функції відгуку від факторів (рис. 1-3).

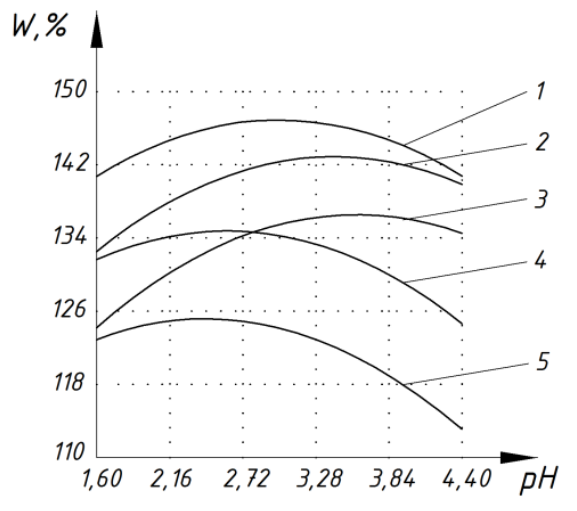

Рисунок 1. Залежність вологовмісту W від значення водневого показника $\mathrm{pH}$ при різній температурі відмочувальної рідини $\mathrm{t}: 1-$ при $\mathrm{t}=50^{\circ} \mathrm{C}$;

$2-$ при $\mathrm{t}=28,7^{\circ} \mathrm{C} ; 3-$ при $\mathrm{t}=20^{\circ} \mathrm{C}$;

$4-$ при $\mathrm{t}=71,3{ }^{\circ} \mathrm{C} ; 5-$ при $\mathrm{t}=80^{\circ} \mathrm{C}$

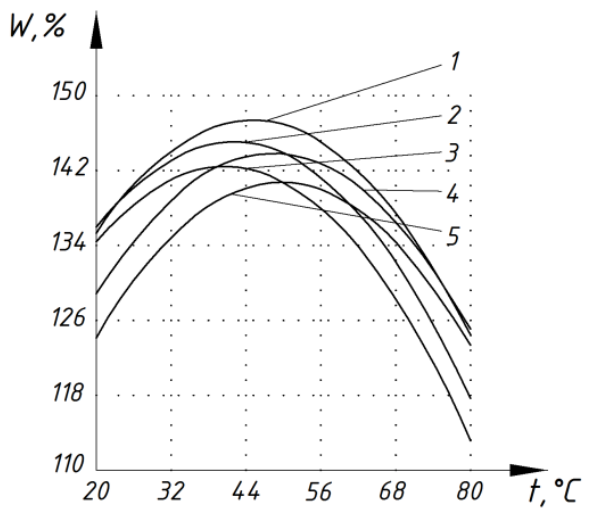

Рисунок 2. Залежність вологовмісту W від температури відмочувальної рідини $\mathrm{t}$ при різних значеннях водневого показника $\mathrm{pH}: 1-$ при $\mathrm{pH}=3,0$; 2 - при $\mathrm{pH}=4,0 ; 3-$ при $\mathrm{pH}=4,4$; $4-$ при $\mathrm{pH}=2,0 ; 5-$ при $\mathrm{pH}=1,6$ 


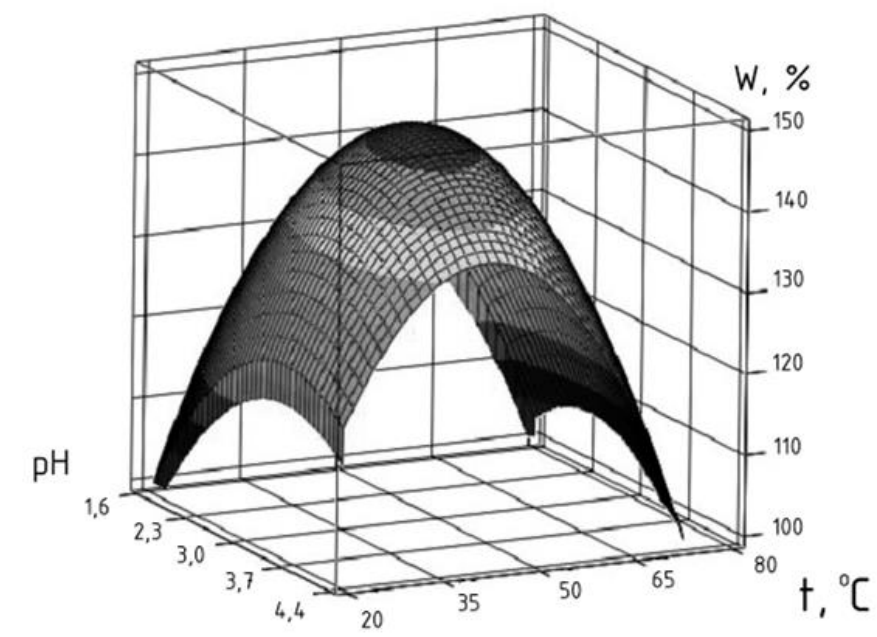

Рисунок 3. Просторова залежність критерію оптимізації процесу відмочування (вологовмісту зразків $W, \%$ ) від факторів (температури $t,{ }^{\circ} \mathrm{C}$

та водневого показника $p H$ відмочувальної рідини)

3 наведених графіків слідує, що функція відгуку має вигляд випуклої поверхні, тобто екстремум - максимальне значення вологовмісту зразка при водневому показнику $\mathrm{pH}$ 2,2...3,8 та температурі відмочувальної рідини $32 \ldots 56^{\circ} \mathrm{C}$.

Для пошуку оптимальних технологічних параметрів процесу зволоження при відмочуванні прісносухих шкур кроля застосовано метод релаксації [4], заснований на переміщенні до оптимуму в напрямку осей координат, вздовж яких функція мети змінюється (зменшується або збільшується) найбільш суттєво.

Оскільки вирішувалась задача максимізації вологовмісту, кроки в напрямку збільшення значень функції мети здійснювались до тих пір, доки значення критерію оптимізації по вибраному осьовому напрямі не припиняло зростати. Критерієм закінчення пошуку служив момент досягнення точки, яка характерна тим, що при русі із неї в будь-якому осьовому напрямі не відбувалось подальше збільшення критерію оптимізації. Причому приймалось до уваги те, що оптимум знаходиться всередині області допустимих відхилень у вимірюваннях факторів, оскільки в точці оптимуму значення часткових похідних близькі до нуля.

При відомому математичному описі об'єкту дослідження у вигляді рівняння другого порядку (2), критерій оптимізації у вихідній точці був рівний 128,542. Ця точка пошуку мала наступні координати: $x_{1}^{(0)}=1 ; x_{2}^{(0)}=1$. Пошук вели спершу в напрямку осі $x_{1}$, в зв'язку з чим зберігали значення $x_{2}^{(0)}=1$ постійним:

$$
y_{1}=146,7658-4,0386 \cdot 1-2,5406 \cdot x_{1} \cdot 1-3,0740 \cdot x_{1}^{2}-8,5704 \cdot 1^{2}
$$

Максимум функції (2) знаходимо із умови:

$$
\frac{d y_{1}}{d x_{1}}=2,5406-2 \cdot 3,0740 \cdot x_{1}
$$

Прирівнявши вираз (5) до нуля і визначивши $x_{1}$, отримаємо: $x_{1}^{(1)}=-0,413$. В новій точці на постійному рівні фіксували фактор $x_{1}$; координати точки наступні: $x_{1}^{(1)}=-0,413 ; x_{2}^{(1)}=x_{2}^{(0)}=1$. Значення критерію оптимізації піднялось до 134,682. Далі вели пошук в напрямку осі $x_{2} 3$ врахуванням нового рівняння для функції мети, яке знайшли із рівняння (2):

$$
y_{2}=146,242-2,990 \cdot x_{2}-8,5704 x_{2}^{2}
$$

Максимум функції мети знайшли із умови: 


$$
\frac{d y_{2}}{d x_{2}}=-2,990-17,141 \cdot x_{2}
$$

звідси $x_{2}^{(2)}=-0,174$.

Координати нової точки: $x_{1}^{(2)}=x_{1}^{(1)}=-0,413 ; x_{2}^{(2)}=-0,174$. Величина критерію оптимізації збільшилась до 146,502 . Після цього рух знову продовжували вздовж осі $x_{1}$, потім знову вздовж осі $x_{2}$ і т.д.

В результаті після чотирьох циклів установили максимальне значення критерію оптимізації, яке склало 147,270. Результати пошуку зведені в табл. 2.

Таблиця 2. Знаходження максимального значення критерію оптимізації

\begin{tabular}{|c|c|c|c|}
\hline \multirow{2}{*}{$\begin{array}{l}\text { № } \\
\text { циклу }\end{array}$} & \multicolumn{2}{|c|}{ Фактори } & \multirow{2}{*}{$\begin{array}{c}\text { Значення критерію } \\
\text { оптимізації } y\end{array}$} \\
\hline & $x_{1}$ & $x_{2}$ & \\
\hline 0 & 1 & 1 & 128,542 \\
\hline 1 & $-0,413$ & 1 & 134,682 \\
\hline 2 & $-0,413$ & $-0,174$ & 146,502 \\
\hline 3 & 0,072 & $-0,174$ & 147,225 \\
\hline 4 & 0,072 & $-0,246$ & 147,270 \\
\hline
\end{tabular}

На рис. 4 показано схему пошуку оптимуму в координатах кодованих величин.

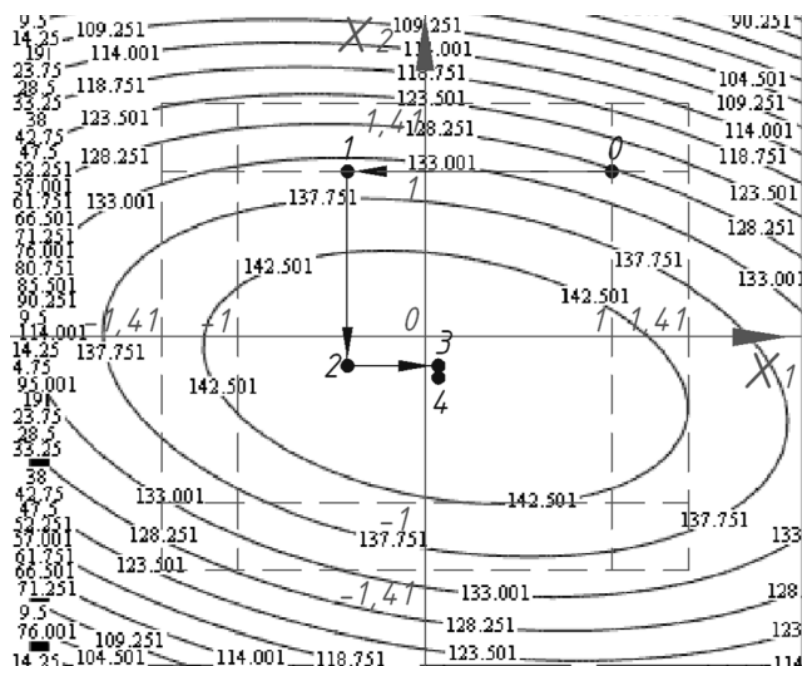

Рисунок 4. Схема пошуку оптимуму при русі методом релаксації

Аналізуючи рис.4, слід відмітити, що при віддаленні від точки екстремуму значення вологовмісту зменшується. Задаючись значенням одного фактора, за рис. 4 можна визначити, як при зміні вологовмісту зразка змінюватиметься інший фактор.

Висновки. В результаті планування експерименту були знайдені оптимальні режими процесу відмочування хутрової сировини. Графічна інтерпретація математичної моделі процесу дійсно відображає поверхню відгуку, що містить екстремум функції.

Отже, оптимальними значеннями технологічних параметрів процесу відмочування $\epsilon$ температура $45 \pm 1$ С та водневий показник $\mathrm{pH} 3,1 \pm 0,1$. При цих значеннях технологічних параметрів досягається максимальне значення вологовмісту шкіри $147 \pm 12 \%$.

1. Савченко Г. В. Прогнозування властивостей шкурок кроля, вичинених з використанням електроактивованої води / Г. В. Савченко, В. П. Коновал, М. С. Беднарчук // Легка промисловість. - К.: Держ.центр. бюро техн. інформації $з$ легкої та текстильної промисл., 2010. - № 4. - С. 32-33.

2. Савченко Г. В. Дослідження впливу електроактивованої води на процес відмочування прісносухих шкур кроля / Г. В. Савченко // Наукові розробки молоді на сучасному етапі: IX Всеукр. ювілейна наук. конф. молодих вчених та студентів, 22-23 квіт. 2010 р.: тези доп. - К.: КНУТД, 2010. - Том II. - С. 82.

3. Цимбаленко О. П. Дослідження впливу $\mathrm{pH}$ електроактивованої води на ії кислотну та лужну ємність / О. П. Цимбаленко, Г. В. Савченко, Б. М. Злотенко // Сучасні екологічно безпечні технології виробництва шкіри та хутра: III міжнар. наук.-практ. конф., присвячена. 80-річчю каф. ТШХ, 27-28 квіт. 2010 р.: зб. наук. праць. - К.: КНУТД, $2010 .-$ С. $170-172$. 
4. Тихомиров В. Б. Планирование и анализ эксперимента (при проведении исследований в легкой и текстильной промышленности). - М.: Легкая индустрия, 1974. - 262 с.

5. Виварский М. С., Лурье М. В. Планирование эксперимента в технологических исследованиях. - К.: Техника, 1975. $-168 \mathrm{c}$

6. Адлер Ю. П., Маркова Е. В., Грановский Ю. В. Планирование эксперимента при поиске оптимальных условий. М.: Наука, 1976. - 280 с.

\section{REFERENCES}

1. Savchenko H.V., Konoval V.P., Bednrrchuk M.S. (2010) The forecasting of the properties of rabbit skins, made using electric activated water. Light industry, 4, 32-33.

2. Savchenko H.V. (2010) The investigation of the influence of electroactivated water on the process of wetting of dry, rabbit hides. Scientific developments of youth at the present stage, volume II, 82

3. Tsymbalenko O.P., Savchenko H.V., Zlotenko B.M. (2010) The investigation of the influence of pH of electroactivated water on its acid and alkaline capacity. Modern ecologically safe technologies of leather and fur production, 170-172.

4. Tikhomirov V.B. (1974) Experiment planning and analysis (when conducting research in the light and textile industry). Light industry, 262.

5. Vivarskii M.S., Lurie M.V. (1975) Experiment planning in technological research. Equipment, 168.

6. Adler Y.P., Markova E.V., Granovskii Y.V. (1976) Planning an experiment when searching for optimal conditions. Science, 280

Ефимчук Г. В., Назарчук Л. В., Селезньов Е. Л., Клименко О. Д., Селезньов Д. Е., Шимчук Ю. П. Оптимизация процесса отмоки пресносухого сырья под влиянием электроактивированной водной среды.

В статье представлены результаты планирования двухфакторного эксперимента, в результате которого установлены оптимальные режимы процесса отмоки мехового сырья. Предложены практические рекомендации использования электроактивированных водных растворов при проведении технологических процессов обработки мехового сырья, а также определены рациональные технологические параметры проведения подготовительных процессов выделки меха.

Ключевые слова: отмока, меховое сырье, $\mathrm{pH}$ водного раствора, электроактивированная вода.

Halyna Yefimchuk, Liudmyla Nazarchuk, Eduard Seleznov, Aleksandr Klymenko, Dmytro Seleznov, Yurii Shymchuk. Optimization of the process soaking fresh-dry raw materials under the influence of electroactivated aqua environment.

The article presents the planning of a two-factor experiment, which resulted in the establishment of optimal regimes of the process of wrapping fur raw materials. Practical recommendations for the use of electroactivated aqueous solutions during technological processes of processing of fur raw materials are offered, as well as rational technological parameters of conducting preparatory processes for finning.

Keywords: soaking, fur raw materials, $\mathrm{pH}$ of an aqueous solution, electroactivated water.

Г. В. ЕФИМЧУК, кандидат технических наук, доцент кафедры отраслевого машиностроения и лесного хозяйства, Луцкий национальный технический университет, Луцк, Украина

Л. В. НАЗАРЧУК, кандидат технических наук, доцент кафедры отраслевого машиностроения и лесного хозяйства, Луцкий национальный технический университет, Луцк, Украина

E. Л. СЕЛЕЗНЬОВ, кандидат технических наук, доцент кафедры отраслевого машиностроения и лесного хозяйства, Луцкий национальный технический университет, Луцк, Украина

O. Д. КЛИМЕНКО, кандидат технических наук, доцент кафедры отраслевого машиностроения и лесного хозяйства, Луцкий национальный технический университет, Луцк, Украина

Д. Е. СЕЛЕЗНЬОВ, кандидат технических наук, старший преподаватель кафедры отраслевого машиностроения и лесного хозяйства, Луцкий национальный технический университет, Луцк, Украина

Ю. П. ШИМЧУК, ассистент кафедры отраслевого машиностроения и лесного хозяйства, Луцкий национальный технический университет, Луцк, Украина

Halyna YEFIMCHUK, Ph. D., Associate Professor of the Depattment of industry mechanical engineering and forestry, Lutsk National Technical University, Lutsk, Ukraine

Liudmyla NAZARCHUK, Ph. D., Associate Professor of the Depattment of industry mechanical engineering and forestry, Lutsk National Technical University, Lutsk, Ukraine

Eduard SELEZNOV, Ph. D., Associate Professor of the Depattment of industry mechanical engineering and forestry, Lutsk National Technical University, Lutsk, Ukraine

Aleksandr KLYMENKO, Ph. D., Associate Professor of the Depattment of industry mechanical engineering and forestry, Lutsk National Technical University, Lutsk, Ukraine

Dmytro SELEZNOV, Ph. D., Senior Lecturer of the Depattment of industry mechanical engineering and forestry, Lutsk National Technical University, Lutsk, Ukraine

Yurii SHYMCHUK, assistant of the Depattment of industry mechanical engineering and forestry, Lutsk National Technical University, Lutsk, Ukraine

Стаття надійшла в редакцію 03.05.2019p. 